\title{
Study on Countermeasures from the Perspective of Imbalance Between Supply and Demand of China's institutional pension
}

\author{
Xiao-Ning ZHU 1,a, Mei-Feng YOU 2,b, \\ ${ }^{1, S c h o o l ~ o f ~ P o l i t i c a l ~ S c i e n c e ~ a n d ~ P u b l i c ~ A d m i n i s t r a t i o n, ~ U n i v e r s i t y ~ o f ~ E l e c t r o n i c ~ S c i e n c e ~ a n d ~}$ \\ Technology, Chengdu, P.R. China, 611731 \\ 2,School of Political Science and Public Administration, University of Electronic Science and \\ Technology, Chengdu, P.R. China, 611731 \\ azhuxn@163.com, bmfyou@foxmail.com
}

Keywords: Institutional Pension, Supply and Demand Imbalance, Countermeasures.

\begin{abstract}
Given the context of several social challenges, such as aging, old aging, sickness and disabilities, China has to focus on the reformation of institutional pension system. Compared with developed countries, China was involved in this "Silver Wave" before well developed. As one of the most important components of pension service system, a relatively complete institutional pension system has been established in China, yet far beyond being perfect. What's more, the impacts of increasing growth for the aging population require further improvement of the institutional pension system. However, the status quo of institutional pension system shows that there is serious imbalance in supply and demand quantity, content and structure. To explore the better development of institutional pension service in China, this paper puts forward several countermeasures to solve these problems by diversified supply subject, accurate supply of content and balanced supply structure, which has strong theoretical and practical significance for the development of institutional pension in China.
\end{abstract}

\section{Introduction}

It is known that China has entered into ageing society since 1998. As shown in Figure 1, until 2015 aged population has increased to 222 million, which takes up $16.1 \%$ of total population, according to the statistics of the Civil Affairs Department. At the same time, it is estimated that the proportion of the aged population will continue raising until 2020. It means China's aging problem is increasingly serious. According to calculation, the number of old aging ( $\geq 80$ years old) will also break 13 million, which accounts for 12.37 percent of the aging population. It also means that the age of old aging is coming.

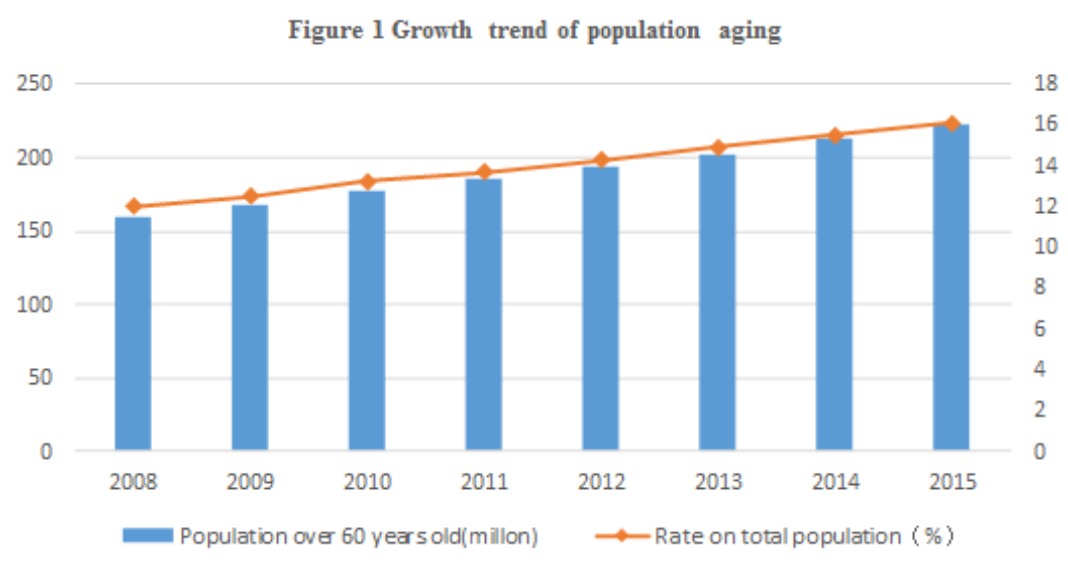

A lot of the old are facing a great possibility of living seperate from their children with the miniaturization of family structure and the increase of 4-2-1 family (a family with four elderly people, two middle-aged and a child). Once the widowed situation occurred, the other partner will be very 
likely to become Empty-Nest Elderly. Also, chronic diseases, the main causes of the disability to the elderly, are increasing when people get older. The number of disabled people over 60 years old has reached 44.16 million, accounting for $53.24 \%$ of the total disabled population, according to the Second China National Sample Survey on Disability.

In conclusion, pension service industry in China is facing aging, old aging, sickness and disabilities. Traditional family supporting has been struggling to cope with the increasingly pension problems. Institutional pension as one of the most important supports of pension service industry, is highly appreciated by the government. As early as 2013, the State Council issued "Opinions on Accelerating the Development of the Pension Service Industry" it further confirms the development targets of China's pension service industry and put forward that "vigorously strengthen the construction of pension institutions" and "supporting social forces to construct pension institutions". The "13th Five-Year plan about national aging career development and pension system construction" also points out that speeding up the reform of public pension institutions, and supporting social forces to set up pension institutions to improve the quality of institutional pension services.

\section{Brief Synopsis of Institutional Pension}

\section{Concept of Institutional Pension}

Institutional pension refers to the old receive free or paid professional pension in pension service institutions which set up by government, enterprises and other individuals.

\section{Type of Institutional Pension}

\section{Social Welfare Institute.}

Social welfare institute is a kind of social welfare services set up by the local Civil Affairs Department, mainly for the adoption of "three-no" elderly(no ability to work, no source of life, no care of the elderly), orphans and disabled children. The cost of social welfare institute is paid by the government.

\section{Nursing Home.}

Nursing home is also be called pension center, generally adopting those elderly who can't afford family pension. Nursing home can be divided into two categories: public pension institutions and private pension institutions, the elderly and their families pay all the costs. Nursing homes belong to commercial institutions becauser they are generally self-financing, but the government will support the development of nursing homes through policy.

\section{Rural Homes for the Elderly.}

Rural homes for the elderly is a part of rural welfare industry, mainly adopting "five-guaranteed" elderly whose costs were paid by the government according to the national minimum living security.

\section{Apartment for the Aged.}

The apartments suitable for elderly pension which is specially built by government. The elderly can buy or rent the apartment to meet their needs. Generally the apartment for aged will be equipped with infirmary and activity room along with the service staff.

\section{The Performance of Imbalance between Supply and Demand of Chinese Institutional Pension}

\section{Imbalance between Supply and Demand Quantities}

According to the statistics of the Civil Affairs Department in 2016, the total number of pension service institutions was 116000 by the end of 2015, which increased by $23.4 \%$ higher than previous in 2014. Beds that institutional pension can provide has reached 3.93 million, only average 28.01 beds for per one thousand elderly people over 65 years old. According to the request raised by "Social 
Pension Service System Construction Plan (2011-2015)", beds provided by national institutional pension should reach a total of 6.6 million, but recently, there are serious shortage on China's pension service supply. For the current tendency, China's pension supply will be insufficient when aging population show an increasing trend while the number of institutional pension bed has shown a negative growth trend after 2013.

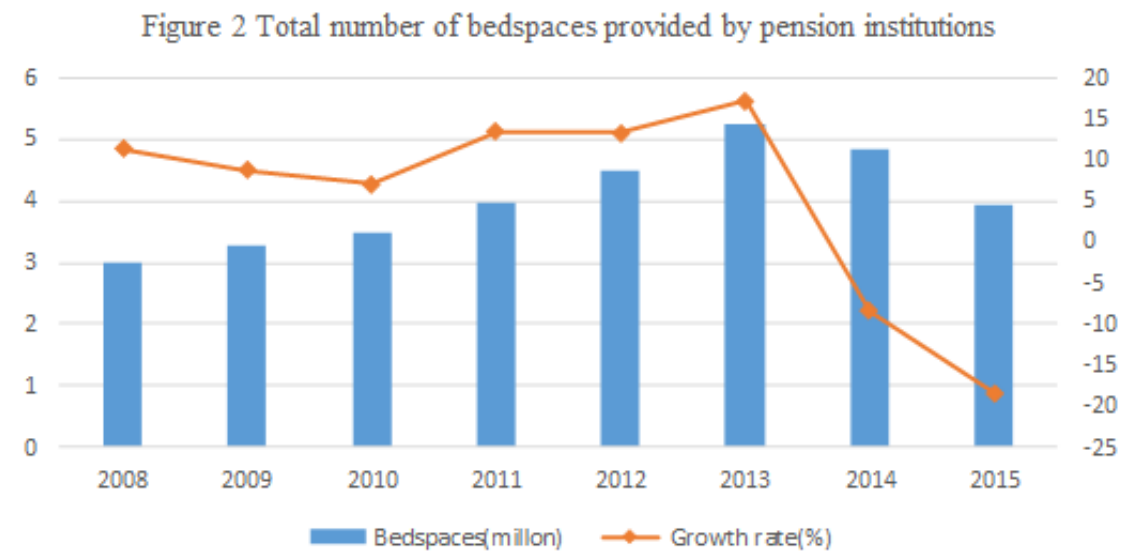

The needs for professional medical and rehabilitation facilities are in sustained growth with the increase in the China's aging chronic disease incidence and more and more sickness and disability in aging population. But professional medial and rehabilitation facilities for aging people is almost vacant in China's institutional pension, private pension institutions more inadequate medical and rehabilitation facilities configurations in particular. At the same time, professional nursing staff also are in shortage and the proportion of health care workers in pension institutions is only $12 \%$.

\section{Imbalance between Supply and Demand Contents}

The scale of China's disabled aged population is increasing rapidly with the increase of chronic diseases in recent years, and all these aged people need long-term professional nursing care. However, pension institution with professional nursing, health care and professional technical skills is in serious shortage in the existing institutional pension. Particularly in private pension institutions, the elderly can only get basic living care from the staff who never get nursing qualification and even never received any professional skill training. While those pension institutions with better medical and nursing can't provide an effective demand because their high-level charges can't be afford by ordinary elderly.

Psychological support is also lacked in institutional pension. Many families hold a "the last choice" attitude to institutional pension because of holding a concept of "raising children for pension". After leaving their own families to adapt to the collective life, the elderly will step into deep loneliness and great emptiness so psychological support from pension institution is in badly need. While a large part of pension institutions can't provide plenty of entertainment activities to enrich the spirit of the elderly.

\section{Imbalance between Supply and Demand Structure.}

Development of social economic and institutional pension are inextricably related. Imbalance social economic development leads to the imbalance institutional pension in China. It shows obvious imbalance between urban and rural, regional imbalance .The development of institutional pension in rural and central, western regions has lagged far behind urban and eastern regions. Meanwhile there are great gaps in institutional pension treatment between elderly in different occupations and identities. There exist great big differences between urban and rural, the East and the West in capital investment and infrastructure and other aspects of China's institutional pension. The development of China's aging career should "focus on urban and rural areas, regional coordinated development" pointed out in "China's aging career development, 12th Five-Year plan". 


\title{
Analysis on the Reasons and Factors of Imbalance between Supply and Demand in China's Institutional Pension
}

\author{
Analysis on the Reasons of Imbalance between Supply and Demand in China's Institutional \\ Pension
}

\section{Ambiguous Responsibility of the Government.}

The government has an unshirkable responsibility in pension service because it is a public service. At present, division of labor in pension service isambiguous because the government cannot aim at their own positioning, which caused offside, absence, dislocation and other problems coexist in pension service. Guidance provided by government was deficiency in the market access, and there is no corresponding participation and incentive mechanism either. Due to the ambiguous pointing of the government, social institutions and enterprises have not been well encouraged and supported, which resulting in the lack of institutional pension market.

\section{Extensive Supply of the Government.}

The government provide an extensive supply to institutional pension. A series of policies and plans aimed at increasing financial investment and promoting social institutions to set up pension institutions has been introduced by the government in recent years. But a large part of the financial investment was used to make up for the pension gap, social organizations build pension institutions was just to reduce the access threshold without effective mechanism in practice. There no thorough stipulation in the staff establishment of pension institutions and service indicators and relevant third-party assessments is also absent, which results in supervision difficulty in China's institutional pension and serious homogenization development.

\section{"Double-Standard" in Institutional Pension.}

Regardless of the capital, facilities and conditions of private pension institutions are far worse than public pension institutions. Private pension institutions need large investments to constructions and facilities when ae the early stage, while the payment almost constitute all income of private pension institution. Public pension institutions have far more superior facilities and supports than private pension institutions because they can get financial support from the government. On the level of institutional development, what general private pension institutions provide is just simple daily care, elderly need to pay higher to choose a private institution with medical and nursing services. While public funded pension institutions always provide complete services at a low price. Unfair competition between private and public pension institutions was caused by these "double-standard" in pension institutions, which dampened the enthusiasm of private pension institutions and inhibit its development.

\section{The Influence Factors of the Imbalance between Supply and Demand of Institutional Pension}

\section{Concept.}

The traditional concept of "Raising children for pension" has taken root in a large number of elderly. The old want to spend their twilight years with their families. As for institutional pension, the majority of elderly people's attitude is the last option. Similarly, many young people think it is unfilial to send their old men to pension institutions. Many elderly people will be uncomfortable in both physical and mental conditions when they enter the pension institution in the early stage for lacking of experience in collective life.

\section{Changes in Family Structure.}

Traditional old-age care is dependent on family members. However, with the miniaturization of Chinese families and the increase of 4-2-1 families, and this pension methods have been gradually 
failed. More and more members have to join the labour market, because the increase of social competition. Thus, they have no time to take care of the elderly, especially the elderly who are unable to care for themselves.

\section{The Non-Standardization of Government Financial Input.}

The government has not standardized the financial investment of the institutional pension, or set the budget alone. In other words, there is a lack of standardization and explicit management for institutional pension funds. For the newly added pension funds, all levels of finance have not been included in the local budget.

\section{The Countermeasure of the Imbalance between Supply and Demand of the Old-Age Institution}

\section{Increase in Supply.}

\section{The Government Plays a Leading Role.}

In other words, the development of the pension industry is inseparable from the government's promotion. In the course of the development of old-age services, the government should make policies, do a good job in supervising, and also standardize the old-age care market, so as to promote the quick and health development of pension market. This requires the government to do the top-level design, to clarify the market access standards for the old-age pension, to standardize the standard procedures for the old-age pension, and to introduce third-party supervision and assessment. At the same time, the government, as the dominant force of old-age care, should integrate the social endowment resources and rationalize the relationship between the government and the various forces in the pension market. Finally, the government needs to provide old-age care for the disadvantaged groups as pension is a public service.

\section{Social Forces are Encouraged to Participate.}

The development of institutional pension is inseparable from the participation of multi-party forces. Firstly, the government should implement the existing preferential policies, at the same time, continue to strengthen institutional pension policy support, such as explore ways to raise funds for different pension funds. Secondly, the government should improve the preferential policies for the private pension institutions. For example, increasing the strength of preferential policies for private pension institutions in the fields of industry, commerce, taxation and water and electricity is a good proposal. The last but not least, The relevant departments should simplify the approval process of pension institutions and encourage multi-party forces to participate in the provision of institutional pension.

\section{Accurate Supply Content.}

\section{Professional Supply.}

It mainly refers to the professionalism of medical care and nursing level. The establishment of standard and professional industry guidelines is the premise of institutional pension development. Furthermore, it is necessary to improve the professional skill level of medical care personnel. Only by continuously improving the professional skills of medical care personnel can be better care. In this way, pension institutions can be recognized by the community. Equally important, the incentive system and the treatment of medical care workers should be improved to stable institutional pension professionals.

\section{Provide a Targeted Supply.}

The supply of pension services needs to be adapted to local conditions rather than uniform supply. To begin with, we need to do a survey and analysis of the needs of the elderly in pension institution. Especially the mental needs of the elderly. While respecting the elderly, the spiritual needs of the 
elderly are also satisfied as much as possible. Humanization and familiarization are the higher goal of institution pension development. That is to say, while respecting their privacy, the elderly in the care institutions feel the warmth of the family.

\section{Balanced Supply Structure}

\section{Balanced Urban and Rural Supply.}

The imbalance of urban and rural economic development has resulted in the imbalance of the supply of old-age resources. For instance, rural old age and old age policy are weaker than towns. In order to balance urban and rural development, we need to rich rural old-age resources through financial means .At the same time, the government should strengthen the power of policy support to the rural, poor areas.

\section{Narrow Regional Differences.}

It means narrowing the imbalances in the development of pension institutions in different regions. Vigorously developing welfare institutions and charities are built in undeveloped regions to develop pension industry. When allocating pension resources, the government should consider regional differences and gradually reduce regional differences.

\section{Conclusion}

The pension problems became more and more acute with the developing of the society. The supporting problem has become seriously that affects social development and must be solved immediately. When facing various conflicts in institutional pension, the government must play the leading role and encourage other social forces to participate, accurate supplying the content, and gradually narrow the gap between urban and rural areas and regions. In this way, China's institutional pension supply and demand imbalance can be solved.

\section{References}

[1] Mu Guangzhong. Difficulties and solution of China's institutional pension development [J]. Journal of central China normal university (the humanities and social sciences edition), 2012, (02): 31-38.

[2] Mu Guangzhong. The aging of population and Suggestions on the development of the service industry [J]. Social governance, 2015, (04): 79-83.

[3] Ni Dongsheng, Zhang. yanfang. The Chinese government buys pension service policy research under the background of imbalance of supply and demand of pension service [J]. Journal of the central university of finance and economics, 2015, (11): 3-13.

[4] Zhang Yanfang. Research to promote the balanced supply and demand of old-age care services to purchase pension service policy of Chinese government [J]. Northwestern population, 2016, (01): $87-93+98$.

[5] Jiang. Chunli. The analysis of China's aging population and the strategy for the 13th five-year plan period [J]. Globalization, 2016, (8): 2016-105 + 135 .

[6] Wu. Yushao, Du Junwu. China's development report on aging (2013) [M]. Social sciences literature publishing house, 2013.

[7] Song Quancheng. Aging population-China's social pension service faces severe challenges [J]. Academic journal, 2016, (02): 122-12

[8] Wang Lili. Analysis on the development of old-age service industry in urban in China. [J] Population journal, 2014, (04): 83-92. 
[9] Zhang Zengfang. The supply and demand contradiction and development idea of institution endowment in the background of aging- data analysis based on xi 'an [J]. Journal of northwestern university (philosophical social science edition), 2012, (05): 35-39. 